\title{
HUBUNGAN STATUS FISIK PRA ANESTESI UMUM DENGAN WAKTU PULIH SADAR PASIEN PASCA OPERASI MASTEKTOMI DI RS IBNU SINA FEBRUARI - MARET 2017
}

\author{
Faisal Sommeng* \\ *Bagian Anastesi Fakultas Kedokteran Universitas Muslim Indonesia
}

\begin{abstract}
Abstrak
Latar belakang: Keganasan yang menyerang wanita yaitu kanker payudara. Kanker yang terbatas pada payudara, pengobatannya hampir selalu pembedahan untuk mengangkat sebanyak mungkin tumor. Terdapat sejumlah pilihan pembedahan, pilihan utama adalah mastektomi yaitu pengangkatan seluruh payudara. Untuk memfasilitasi operasi ini, anestesi umum merupakan teknik yang paling sering dipilih. Untuk menentukan prognosis ASA (American Society of Anesthesiologists) membuat klasifikasi berdasarkan status fisik pasien pra anestesi yang membagi pasien ke dalam 5 kelompok atau kategori dari ASA I - V.Evaluasi pra anestesi pada dasarnya bertujuan untuk mengurangi morbiditas dan mortalitas perioperatif dan untuk menghilangkan kecemasan pasien. Metode: Penelitian ini merupakan penelitian analitik observasional dengan pendekatan cross sectional dengan menggunakan teknik purposive sampling. Sampel berjumlah 8 orang yang memenuhi kriteria inklusi dan ekslusi di RS Ibnu Sina. Pengumpulan data dilakukan dengan menggunakan kuesioner data yang berupa daftar isian untuk mencatat status fisik pra anestesi umum dan waktu pulih masing-maisng pasien, serta lembar penilaian skala modifikasi sedasi Ramsay untuk mengukur tingkat sedasi pada pasien. Analisa data pada penelitian ini digunakan uji statistik bivariat menggunakan metode analisis korelasi Spearman rho. Hasil: Dari 8 sampel yang diperoleh, didapatkan 2 responden (25\%) memiliki status fisik pra anestesi umum ASA I, 4 responden (50\%) memiliki status fisik praanestesiumum ASAII, dan 2 responden (25\%) memilikistatusfisikpra anestesiumumASA III. Pada penelitianinijuga dilakukan pengukuran waktu pulihsadar darianestesiumumyaitu waktu yang dihitung mulai voltile ditutup yang di lakukan pada jahitan terakhir kulit sampai dengan pasien mencapai modifikasi skala sedasi ramsay 2 dimana pasien dapat mencapai tingkat sedasi yang ringan, kooperatif, berorientasi dan tenang. Di dapatkan perbedaan rerata waktu pulih sadar pasien pasca operasi mastektomi dengan status fisik pra anestesi umum kirteria ASA1(12 menit),ASAII (26 menit 25 detik) dan ASAIII (36 menit). Darihasil pengujian data menunjukkan nilai sig. (2-tailed) 0,025 < 0,05, maka artinya terdapat hubungan yang signifikan (berarti) antara variabel independen dan variabel dependen sehingga $\mathrm{H}_{\mathrm{o}}$ ditolak dan $\mathrm{H}_{1}$ diterima yang artinya ada hubungan antara status fisik pra anestesi umum maka waktu pulih pasien pasca operasi mastektomi. Kesimpulan: Hasil penelitian di RS Ibnu Sina februari - Maret 2017 menunjukkan adanya hubungan antara status fisik pra anestesi umum dengan
\end{abstract}


waktu pullih pasien pasca operasi mastektomi dengan nilai sig. (2-tailed) 0,025 < 0,05 yang berarti $\mathrm{H}_{1}$ diterima.

Kata Kunci: Anestesi Umum, Status Fisik ASA, Waktu Pulih, Mastektomi

\section{PENDAHULUAN}

Semakin berkembangnya zaman banyak terdapat masalah kesehatan yang terjadibaik padawanita maupun pria. Salah satu masalah kesehatan yang sering ditemukan di seluruh dunia adalah keganasan yang menyerang wanita yaitu kanker payudara. Kanker payudara merupakan keganasan paling sering pada wanita di negara maju dan nomor dua setelah kanker serviks di negara berkembang dan merupakan 29\% dariseluruh kankeryang didiagnosis setiaptahun. Secara keseluruhan merupakan penyebab kematian nomor dua kanker setelah kanker paru-paru. ${ }^{1}$

Insiden kanker payudara terus meningkat, saat ini lebih dari 170.00o kasus ditemukan per tahun. Insidennya bervariasi di tiap negara, tertinggi di Swedia dengan rata-rata insiden 129.5/100.000 wanita dan terendah di Jepang 37.0/100.00o wanita (International Opportunities in Cancer Management, SRI International, 1994). Di negara berkembang insiden lebih tinggi di Amerika Selatan, Karibia, Asia Barat dan Afrika Utara. ${ }^{1}$

Menurut WHO 8-9\% wanita akan mengalami kanker payudara. Pada tahun 2000 diperkirakan 1,2 juta wanita terdiagnosis kanker payudara dan lebih dari 700.000 meninggal. Ini menjadikan kanker payudara sebagai jenis kanker yang paling banyak ditemukan pada wanita. Setiap tahun lebih dari 250.00o kasus baru kanker payudara terdiagnosis di Eropa dan kurang lebih 175.000 di USA. Ditemukan kira- kira 210.000 kasus baru dan 76.ooo kematian setiaptahun di Uni Eropa. ${ }^{2}$

Di Indonesia kanker payudara merupakan kanker dengan insiden tertinggi nomor dua setelah kanker serviks dan terdapat kecenderungan meningkat dari tahun ke tahun. Sebagian besar keganasan payudara datang pada stadium lanjut. Jumlah kanker payudara di Indonesia didapatkan kurang lebih 23.140 kasus baru setiap tahun (200.000.000 populasi). ${ }^{1}$

Kanker yang terbatas pada payudara, pengobatannya hampir selalu pembedahan (yang dilakukan segera setelah diagnosa ditegakkan) untuk mengangkat sebanyak mungkin tumor. Terdapat sejumlah pilihan pembedahan, pilihan utama adalah mastektomi yaitu pengangkatan seluruh payudara. Untuk memfasilitasi operasi ini, anestesi umum merupakan teknik yang paling sering dipilih.

Anestesi umum (General Anestesi) adalah tindakan menggunakan zat anestesi yang bekerja di susunan saraf pusat sehingga dapat menimbulkan efek hipnotik (menidurkan), efek analgesi dan efek relaksasi otot yang dikenal sebagai trias anestesi. ${ }^{6,7}$ Sebagai efek tambahan, pada anestesi umum juga terjadi hilangnya refleks protektif, termasuk hilangnya kemampuan untuk mempertahankan jalan napas tetap terbuka. Seseorang yang memperoleh anestesi umum akan kehilangan kemampuan untuk memberi respon terhadap perintah verbal maupun rangsang taktil. ${ }^{3}$ 
Untuk menentukan prognosis ASA (American Society of Anesthesiologists) membuat klasifikasi berdasarkan status fisik pasien pra anestesi yang membagi pasien ke dalam 5 kelompok atau kategori sebagai berikut: ASA I, yaitu pasien dalam keadaan sehat yang memerlukan operasi. ASA II, yaitu pasien dengan kelainan sistemik ringan sampai sedang baik karena penyakit bedah maupun penyakit lainnya. ASA III, yaitu pasien dengan gangguan atau penyakit sistemik berat yang belum mengancam jiwa. ASA IV, yaitu pasien dengan kelainan sistemik berat yang secara langsung mengancam jiwanya. ASAV,yaitu pasien yang terancam meninggal dan diperkirakan tidak bertahan dalam 24 jam dengan atau tanpa operasi. Klasifikasi ASA juga dipakai pada pembedahan darurat dengan mencantumkan tanda darurat $(\mathrm{E}=$ emergency), misalnya ASA $1 \mathrm{E}$ atau IIIE. ${ }^{4}$

Evaluasi pra anestesi pada dasarnya bertujuan untuk mengurangi morbiditas dan mortalitas perioperatif dan untuk menghilangkan kecemasan pasien. Evaluasi ini juga bermanfaat dalam membangun hubungan baik antara dokter dan pasien, mengetahui kelainan bedah yang dialami pasien dan gangguan kesehatan lain yang menyertainya, untuk menyusun rencana perawatan anestesi perioperatif, dan memberikan informed consent untuk rencana anestesi.Evaluasiinijuga meliputi konsultasi mengenai riwayat penyakit pasien, dan penjelasan mengenai pilihan jenis anestesi dan obat-obatan yang digunakan serta keuntungan dan kerugian dari masing-masing jenis anestesi dan memprediksi komplikasi pasca anestesi tersebut. ${ }^{5}$

Berdasarkan uraian tersebut di atas, peneliti tertarik untuk meneliti adakah hubungan antara status fisik pra anestesi umum dengan waktu pulih pasien pasca operasi mastektomi di RS Ibnu Sina.

\section{METODE PENELITIAN}

\section{Desain Penelitian}

Rancangan yang digunakan dalam penelitian ini adalah penelitian analitik observasional menggunakan survey cross sectional yaitu suatu penelitian untuk mempelajari dinamika korelasi dengan cara pendekatan, observasi, observasi partisipatif atau pengumpulan data sekaligus pada suatu saat (point time approach), artinya tiap subjek penelitian hanya diobservasi sekali saja dan pengukuran dilakukan terhadap status karakter atau variabel subjek pada saat pemeriksaan, namun hal initidak berarti bahwa semua subjek penelitian diamati pada waktu yang sama. Rancangan penelitian ini digunakan untuk mengidentifikasi hubungan status fisik pra anestesi umum dengan waktu pulih pasien pasca opersi mastektomi di RS Ibnu Sina Tahun Januari - Maret 2017.

\section{Variabel Penelitian}

1. Variabel Independen: Status fisik pra anestesi umum dalam kriteria ASA (AmericanSociety of Anesthesiology)

2. Variabel Dependen:Waktu pulih pasien pasca operasi mastektomi

\section{Tempat dan Waktu Penelitian}

Penelitian ini direncanakan akan diadakan di Kota Makassar tepatnya dengan mengumpulkan sampel di ruang pulih sadar Instalasi Bedah Sentral RS Ibnu Sina Kota Makassar. Penelitian dilakukan selama 2 bulan dimulai Februari 2017 sampai Maret 2017. 


\section{Definisi Operasional}

Status Fisik Pra Anestesi Umum

1) Definisi Operasional

Status fisik pra anestesi umum adalah hasil evaluasi pra anestesi yang dilakukan oleh dokter anestesi yang dicantumkan pada rekam medik pasien.

2) Alat Ukur

Alat ukuryang digunakan adalah rekam medik.

3) Kriteria Objektif

Status fisik pra anestesi umum dalam kriteria ASA (American Society of Anesthesiology):

a. ASA I: pasien dalam keadaan sehat yang memerlukan operasi

b. ASA II: pasien dengan kelainan sistemik ringan sampai sedang baik karena penyakit bedah maupun penyakit lainnya.

c. ASA III: pasien dengan gangguan atau penyakit sistemik berat yang belum mengancam jiwa.

d. ASA IV: pasien dengan kelainan sistemik berat yang secara langsung mengancam jiwanya.

e. ASA V: pasien yang terancam meninggal dan diperkirakan tidak bertahan dalam 24jam dengan atau tanpa operasi.

4) Skala Ukur

Skala Ordinal

\section{Waktu Pulih}

1) Definisi Operasional

Waktu pulih sadar dari anestesi umum dapat didefinisikan sebagai suatu keadaan transisi dari status tidur ke status kesadaran penuh.
2) Alat Ukur

Alat ukur yang digunakan adalah kuesioner dengan menggunakan modifikasi skala sedasi Ramsay.

3) Kriteria Objektif

Modifikasi Skala Sedasi Ramsay:

1 Pasien dengan kesadaran penuh

2 Tingkat sedasi ringan, pasien kooperatif, berorientasi dan tenang

3 Tingkat sedasi sedang, pasien dapat merespon saat diperintah.

4 Tingkat sedasi dalam, pasien menunjukkan respon yang cepat terhadap rangsangan

5 Tingkat sedasi dalam, pasien menunjukkan respon hanaya saat di berikan rangsangan nyeri

6 Tingkat sedasi dalam, pasien tidak menunjukkan adanya respon

4) Skala Ukur

Skala Ordinal

Waktu pulih sadar pasien dihitung mulai voltile ditutup yang di lakukan pada jahitan terakhir kulit sampai dengan pasien mencapai modifikasi skala sedasi ramsay 2.

\section{Populasi dan Sampel} Populasi

a. Populasi Target: Semua pasien pasca operasi mastektomi yang memperoleh anestesi umum yang ada di Kota Makassar.

b. Populasi Terjangkau: Semua pasien pasca operasi mastektomi yang memperoleh anestesi umum yang menjalani operasi di RS. Ibnu Sina Kota Makassar. 


\section{Sampel}

Sampel penelitian adalah populasi terjangkau dari populasi target yang memenuhi kriteria inklusi dan kriteria eksklusi. Teknik pengambilan sampel yang digunakan adalah teknik purposive sampling yaitu, teknik penentuan sampel berdasarkan kriteria tertentu dengan pertimbangan tertentu.

\section{Kriteria Penelitian}

Kriteria Inklusi:

Kriteria Inklusi merupakan kriteria dimana subjek penelitian mewakili sampel penelitian yang memenuhi syarat sebagai sampel. Kriteria inklusi dalam penelitian ini adalah:

1) Bersedia diteliti

2) Pasien pasca operasi mastektomi

3) Memperoleh anestesi umum dengan anestesi inhalasi isofluran

4) Pasien Berusia antara 35 - 65 tahun Kriteria Eksklusi:

Kriteria eksklusi merupakan kriteria dimana subjek penelitian tidak dapat mewakili sampel karena tidak memenuhi syarat sebagai sampel penelitian. Kriteria eksklusi dalam penelitian ini adalah:

1) Pasien deangan status fisikASAIV-V

2) Alergi dengan salah satu obat yang digunakan

3) Menggunakan alat transaqulizer sebelum operasi

4) Pasien DM dengan kadar gula darah tak terkontrol

\section{Kriteria Drop out}

1) Waktu pulih lebih dari 4 jam

2) Menjalani perawatan di ICU
3) Perdarahan hebat dan terjadi shock selama operasi

\section{Cara Pengambilan Data}

Alat Pengumpulan Data

Alat yang digunakan dalam penelitian ini adalah kuesioner data yang berupa daftar isian untuk mencatat status fisik pra anestesi umum dan waktu pulih masing-masing pasien, sertalembarpenilaian skalamodifikasisedasi Ramsay untuk mengukur tingkat sedasi pada pasien.

\section{Pengumpulan Data}

Data dalam penelitian ini diperoleh dari data primer yang diperoleh melalui observasi langsung terhadap pasien di ruang pulih sadar Instalasi Bedah Sentral RS Ibnu Sina dan data sekunder yaitu dari hasil pencatatan rekam medik dari hasil pemeriksaan pasien pra anestesi di RS Ibnu Sina.

\section{Analisis dan Penyajian Data Analisis Data}

Data yang diperoleh telah dilakukan pemeriksaan kebenaran, editing, dikoding, ditabulasi dan dimasukkan kedalam komputer. Jenis analisis data yang digunakan dalam penelitian ini adalah analisis bivariat.

Analisis bivariat dilakukan terhadap dua variabel yang diduga berhubungan atau berkorelasi. Analisis bivariat dilakukan terhadap dua variabel yang diteliti yaitu status fisik pra anestesi umum dengan waktu pulih pasien pasca operasi mastektomi. Dalam penelitian ini uji statistik bivariat menggunakan metode analisis korelasi Spearman. Uji koefisien spearman digunakan untuk melihat kekuatan hubungan antara dua variabel yang memiliki skala pengukuran ordinal, yaitu melihat kekuatan hubungan 
antara variabel independen dan variabel dependennya.

\section{Penyajian Data}

Data yang telah diolah disusun dan disajikan dalam bentuk tabel atau grafik disertai dengan penjelasan.

\section{HASIL DAN PEMBAHASAN}

\section{Hasil Penelitian}

Penelitian ini dilaksanakan di Rumah Sakit Ibnu Sina Makassar yang terletak di Jalan Urip Sumoharjo Km. 5, Kota Makassar, SulawesiSelatan 90241. Penelitian dilakukan pada tanggal 3 Februari hingga 15 Maret
2017 dengan menggunakan metode purposive sampling yang sesuai dengan kriteria inklusi dan ekslusi diperoleh jumlah sampel penelitian sebanyak 8 orang. Data yang didapatkan kemudian diolah dengan bantuan program Microsoft Office Excel 2007 dan Statistical Package for the Social Sciences 22 (SPSS 22).

Dari8sampelyangdiperoleh,didapatkan 2 responden (25\%) memiliki status fisik pra anestesi umum ASA I, 4 responden (50\%) memiliki status fisik pra anestesi umum ASA II, dan 2 responden (25\%) memiliki status fisik pra anestesi umum ASA III, sebagaimana tercantum dalam tabel 1.

Tabel 1. Distribusi frekuensi responden berdasarkan status fisik pra anestesi umum kriteria ASA

\begin{tabular}{ccccc}
\hline \hline $\begin{array}{c}\text { Status fisik pra } \\
\text { anestesi umum } \\
\text { kriteria ASA }\end{array}$ & Frequency & Percent & Valid Percent & $\begin{array}{c}\text { Cumulative } \\
\text { Percent }\end{array}$ \\
\hline $\mathbf{1}$ & 2 & 25.0 & 25.0 & 25.0 \\
\hline 2 & 4 & 50.0 & 50.0 & 75.0 \\
\hline 3 & 2 & 25.0 & 25.0 & 100.0 \\
\hline Total & 8 & 100.0 & 100.0 & \\
\hline
\end{tabular}

Sumber: data primer diolah dengan SPSS 22, 2017

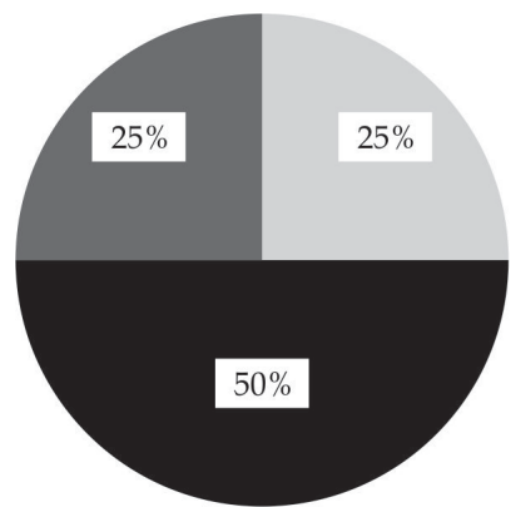

Diagram 1. Distribusi frekuensi responden berdasarkan status fisik pra anestesiumum kriteria ASA

Sumber: data primer diolah dengan SPSS 22, 2017
Pada penelitian ini juga dilakukan pengukuran waktu pulih sadar dari anestesi umumyaitu waktuyang dihitung mulaivoltile ASA 1 ditutupyang di lakukan padajahitan terakhir ASA 2 kulit sampai dengan pasien mencapai ASA 3 modifikasi skala sedasi ramsay 2 dimana pasien dapat mencapai tingkat sedasi yang ringan, kooperatif, berorientasi dan tenang. Di dapatkan perbedaan rerata waktu pulih sadar pasien pasca operasi mastektomi dengan status fisik pra anestesi umum kirteria ASA 1 (12 menit), ASA II (26 menit 25 detik) dan ASA III ( 36 menit) pada penelitian ini. Hal ini dapat dilihat pada tabel 2 . 
Tabel 2. Rerata waktu pulih sadar responden dengan status fisik pra anestesi umum kriteria ASA I, II, dan III

\begin{tabular}{cccc}
\hline $\begin{array}{c}\text { Status fisik pra } \\
\text { anestesi umum } \\
\text { kriteria ASA }\end{array}$ & Mean & N & Std. Deviation \\
\hline $\mathbf{1}$ & 12.00 & 2 & 4.243 \\
2 & 28.00 & 4 & 9.764 \\
3 & 36.00 & 2 & 4.243 \\
\hline Total & 25.13 & 8 & 10.343 \\
\hline
\end{tabular}

Sumber: data primer diolah dengan SPSS 22, 2017

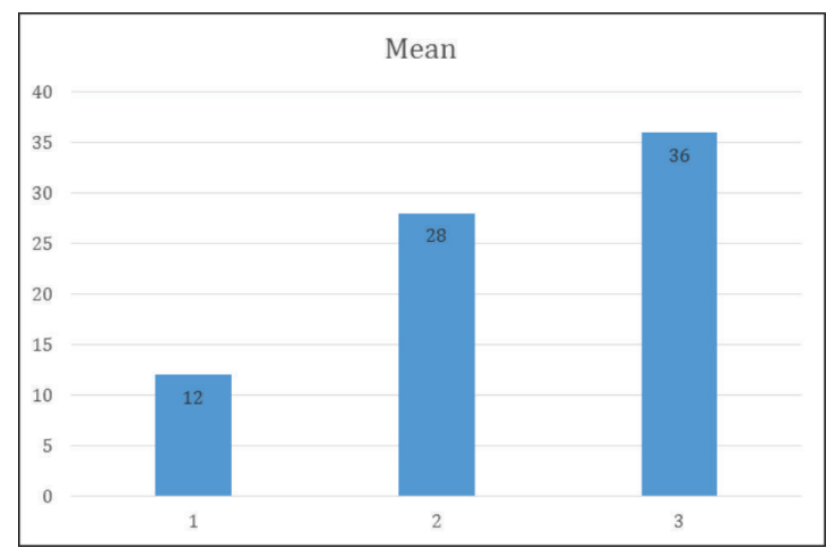

Untuk mengetahui ada tidaknya hubungan status fisik pra anestesi umum dengan waktu pullih pasien pasca operasi mastektomi dilakukan uji statistik Rank Spearman. Adapun hasil analisis data tersebut sebagai berikut:

Diagram 2. Rerata waktu pulih sadar responden dengan status fisik pra anestesi umum kriteria ASA I, II, dan III

Sumber: data primer diolah dengan SPSS 22, 2017

Tabel 3. Hubungan status fisisk pra anestesi umum dengan waktu pulih sadar pasien pasca operasi mastektomi

\begin{tabular}{|c|c|c|c|c|}
\hline & & & $\begin{array}{l}\text { Status Fisik Pra } \\
\text { Anestesi Umum }\end{array}$ & $\begin{array}{l}\text { Waktu Pulih } \\
\text { Pasca Opersi } \\
\text { Mastektomi }\end{array}$ \\
\hline & \multirow{3}{*}{$\begin{array}{l}\text { Status Fisik Pra } \\
\text { Anestesi Umum }\end{array}$} & $\begin{array}{l}\text { Correlation } \\
\text { Coefficient }\end{array}$ & 1,000 &, $772^{* *}$ \\
\hline & & Sig. (2-tailed) & . & ,025 \\
\hline \multirow[t]{4}{*}{ Spearman's rho } & & $\mathrm{N}$ & 8 & 8 \\
\hline & \multirow{3}{*}{$\begin{array}{l}\text { Waktu Pulih Pasc } \\
\text { Opersi Mastektomi }\end{array}$} & $\begin{array}{l}\text { Correlation } \\
\text { Coefficient }\end{array}$ &, $772^{* *}$ & 1,000 \\
\hline & & Sig. (2-tailed) &, 025 & - \\
\hline & & $\mathrm{N}$ & 8 & 8 \\
\hline
\end{tabular}

Sumber: data primer diolah dengan SPSS 22, 2017

Berdasarkan tabel 3, analisis korelasi dengan menggunakan metode Spearman program SPSS VS 22. Nilai koefisien korelasi dengan metode Spearman menunjukkan nilai yang lebih besar dari o,ooo yaitu 0,772.
Sedangkan nilai pada Sig.(2-tailed) atau nilai probabilistiknya menunjukkan nilai o,025.

Berdasarkan analisis korelasi dengan menggunakan metode Spearman maka hasil tersebut menolak Ho, yaitu antara status 
fisik pra anestesi umum dengan waktu pullih pasien pasca operasi mastektomi terdapat hubunganyang signifikan antara satu dengan yang lain. Hal ini berarti terdapat hubungan yang signifikan antara status fisik pra anestesi umum dengan waktu pullih pasien pasca operasi mastektomi.

\section{PEMBAHASAN}

Hasil penelitian menunjukkan bahwa hubungan status fisik pra anestesi umum dengan waktu pullih pasien pasca operasi mastektomi di Rumah Sakit Ibnu Sina Makassar adalah adanya kecenderungan semakin baik status fisik pra anestesi umum maka waktu pullih pasien pasca operasi mastektomi semakin cepat. Hal ini sejalan dengan yang dikemukakan oleh Daniel D. Moos bahwa Evaluasi pra anestesi adalah tindakan pemantauan pertama yang didokumentasikan sebagaiidentifikasiawalterhadappasienyang akan menjalani pembedahan, dimana hal ini dilakukan untuk menjamin tidak terjadinya kekeliruan pasien. Waktu pembedahan, nama pasien, rencana tindakan operasi, nama ahli bedah, keluarga pasien, pelaksana anestesi, tempat tinggal pasien, ruang perawatan dan nomor tempat tidur, berat badan, tinggi badan dan tanda-tanda vital sebelum operasi yang harus didokumentasikan pada evaluasi pra anestesi ini dimana status fisik pra anestesi merupakan salah satu faktor yang ikut mendukung kembalinya fungsi vital pasien seperti sebelum menjalani pembedahan dan anestesi setelah pengakhiran tindakan anestesi itu sendiri disamping faktor - faktor lain yang ikut berperan dalam mempengaruhi waktu pulih sadar pasien. ${ }^{19}$
Dari hasil pengumpulan data diperoleh jumlah responden yang memiliki status fisik pra anestesi umum ASA II lebih banyak dibandingkan dengan responden status fisik ASA I dan III, dengan proporsi responden yang memiliki status fisik pra anestesi umum ASA II sebanyak 4 responden (50\%), ASA II sebanyak 2 responden (25\%) dan ASA III sebanyak 2 responden (25\%). Jumlah responden dengan status fisik pra anestesi umum ASA II lebih banyak dibandingkan ASA I dan ASAIII karena adanya gangguan sistemik ringan atau kelainan laboratorium sedikit saja sudah dikategorikan ke dalam status fisik ASA II.

Rerata waktu pulih pasien dengan status fisik pra anestesi umum ASA I adalah 12 menit dengan simpang baku \pm 4,2 menit. Lama waktu pulih minimum pada pasien dengan status fisik pra anestesi umum ASA I adalah 9 menit dan maksimum selama 15 menit. Rerata waktu pulih pasien dengan status fisik pra anestesi umum ASA II adalah 28 menit dengan simpang baku \pm 9,7 menit. Lama waktu pulih minimum pada pasien dengan status fisik pra GA ASA II adalah 20 menit dan maksimum selama 42 menit. Sedangkan rerata waktu pulih pasien dengan status fisik pra anestesi umum ASA III adalah 36 menit dengan simpang baku \pm 4,2 menit. Lama waktu pulih minimum pada pasien dengan status fisik pra anestesi umum ASA I adalah 33 menit dan maksimum selama 39 menit.

Namun pada tabulasi silang terdapat 1 responden dengan status fisik pra anestesi umum ASA II yang memiliki waktu pulih 42 menit, sementara responden dengan status fisik pra anestesi umum ASA II lainnya hanya memiliki waktu pulih dibawah 27 
menit. Satu orang responden dengan waktu pulih 42 menit yang dikategorikan memiliki status fisik ASA II memiliki $\mathrm{Hb}$ dibawah normal. Berdasarkanteoriyang ada, transpor oksigen ke jaringan perifer ditentukan oleh kardiak output(COdalaml/menit) dan kadar oksigen darah arterial $\left(\mathrm{CaO}_{2}\right.$ dalam $\left.\mathrm{mg} / \mathrm{dl}\right)$, dimana $\mathrm{CaO}_{2}$ ditentukan oleh konsentrasi hemoglobin dan saturasi oksigen $\mathrm{Hb}$. Sehingga dapat dengan mudahterlihat bahwa penurunan kadar $\mathrm{Hb}$ memberi efek yang besar terhadap transport oksigen ke jaringan perifer meskipun mekanisme kompensasi terjadi. Tindakan operasi dan anemia akan memberikan stressor terhadap miokardium untuk meningkatkan CO dan transpor oksigen secara global. Untuk melakukan itu kebutuhan oksigen miokardium sendirijuga meningkat, caranya adalah dengan meningkatkan aliran darah koroner. Ketika kadar Hb turun dibawah normal visikositas plasma juga menurun sehingga meningkatkan aliran darah perifer dan akhirnya berpengaruh terhadap meningkatnya aliran balik vena ke atrium kanan. Dengan demikian terjadilah peningkatan volumesekuncup sesuai dengan hukum Starling. Penurunan visikositas plasma juga berakibat mengurangi afterload, yang merupakan salah satu mekanisme penting untuk mempertahankan CO. Lebih jauh lagi, peningkatan $\mathrm{CO}$ yang dimediasi kemoresptor aorta menginduksi saraf simpatis yang memediasi peningkatan kontraksi miokardium dan frekuensi denyut jantung. Hal tersebut menjadi salah satu faktor yang menyebabkan perlu waktu yang relatif lebih lama untuk mengembalikan kondisihemodinamikkekeadaan stabilpasca operatifpada pasien dengan anemia. ${ }^{20,21}$
Selanjutnya untuk mencari hubungan antara status fisik pra anestesi umum dengan waktu pullih pasien pasca operasi mastektomi digunakan uji Bivariate Correlation untuk mencari hubungan antara dua variabel. Nilai koefisien korelasi dengan metode Rank Spearman menunjukkan nilai yang lebih besar dari o,ooo yaitu 0,772. Sedangkan nilai pada Sig. (2-tailed) atau nilai probabilistiknya menunjukkan nilai o,o25.

Dari output diatas, diperoleh angka koefisien korelasi sebesar $0,772^{* *}$. Artinya tingkat kekuatan hubungan (korelasi) antara status fisik pra anestesi umum dengan waktu pullih pasien pasca operasi mastektomi 0,772 atau hubungan yang sangat kuat. Tanda bintang $\left({ }^{* *}\right)$ artinya korelasi bernilai signifikan pada angka signifikasi sebesar 0,025. Angka koefisien korelasi pada hasil di atas, bernilai positif, yaitu 0,772, sehingga hubungan kedua variabel tersebut bersifat searah (jenis hubungan searah), dengan demikian dapat diartikan bahwa dengan semakin baik status fisik pra anestesi umum maka waktu pullih pasien pasca operasi mastektomi juga akan cepat. Berdasarkan output diatas, diketahui nilai signifikasi atau sig. (2-tailed) sebesar 0,025, karena nilai sig. (2-tailed) 0,025<0,05, maka artinyaterdapat hubungan yang signifikan (berarti) antara variabel independen dan variabel dependen.

Data yang terkumpul diolah secara manual dengan menggunakan Microsoft Excel dan program SPSS VS 22 dengan uji Correlation Bivariate metode Rank Spearman, disajikan dalam bentuk tabel. Jika nilai Sig $(0,000)<\alpha$ maka $H_{o}$ ditolak. Jadi hubungan kedua variabel adalah signifikan. Jika nilaiSig (o,ooo) > a maka $\mathrm{H}_{\mathrm{o}}$ diterima, jadi tidak ada hubungan kedua variabel yang signifikan. 
Berdasarkan analisis korelasi dengan menggunakan metode Rank Spearman maka hasil tersebut menolak $\mathrm{H}_{\mathrm{o}}$ yaitu, antara status fisik pra anestesi umum dengan waktu pullih pasien pasca operasi mastektomi terdapat hubungan yang signifikan. Karena hasil penelitian menunjukkan terdapat hubungan yang signifikan, maka dengan ini dapat dinyatakan bahwa semakin baik status fisik pra anestesi umum maka semakin cepat waktu pullih pasien pasca operasi mastektomi.

\section{Keterbatasan Penelitian}

Meskipunberbagaiupayatelahdilakukan agar mendapat data yang akurat, namun demikian adanya berbagai keterbatasan yang bersifat teknis maupun non teknis, maka perlu dikemukakan beberapa hal berkaitan dengan keterbatasan yang muncul dalam penelitian ini, diantaranya adalah sebagai berikut:

a. Kurangnyajumlah sampel penelitian

b. Keterbatasan waktu membuat penelitian yang mengakibatkan kurang maksimalnya hasil penelitian

c. Sulitnya responden untuk diajak kerjasama, karena waktu istirahat yang tersita karena mengisi kuesioner penelitian.

\section{PENUTUP}

\section{Kesimpulan}

Berdasarkan hasil penelitian dan pembahasan maka dapat disimpulkan sebagai berikut:

1. Rerata waktu pulih pasien di ruang pulih sadar instalasi bedah sentral Ibnu Sina pada pasien dengan status fisik pra anestesi umum ASA I adalah 12 menit.

2. Rerata waktu pulih pasien di ruang pulih sadar instalasi bedah sentral Ibnu
Sina pada pasien dengan status fisik pra anestesi umum ASA II adalah 28 menit

3. Rerata waktu pulih pasien di ruang pulih sadar instalasi bedah sentral Ibnu Sina pada pasien dengan status fisik pra anestesiumum ASAIII adalah 36 menit

4. Secara statistik terdapat perbedaan bermakna antara waktu pulih pasien dengan status fisik pra anestesi umum kriteria ASA I, ASA II dan ASA III.

\section{Saran}

1. Diperlukan jumlah sampel yang lebih banyak agar dapat memperlihatkan hasil yang lebih baik.

2. Diperlukan penelitian lebih lanjut dengan membandingkan status fisik pra anestesi yang berbeda dan pada operasi yang berbeda.

\section{DAFTAR PUSTAKA}

1. Suryatno. 2010. Pasaribu ET., Bedah Onkologi Diagnostik dan Terapi. Jakarta: Sagung Seto.

2. Azamris. 2012. Analisis Faktor risiko pada Pasien Kanker Payudara di Rumah Sakitdr.M. Djamil Padang. Available from: URL: http://www.kalbe.co.id. Diakses pada 16 Mei2006.

3. Rogers A, Gordon RC. 2005. Anesthesia. In: Gordon RC, ed. Manipulation Under Anesthesia Concept in Theory and Application. New York: Taylor \& Francis Group.

4. Dachlan R. 1989. Persiapan Pra Anestesia. Dalam: Anestetiologi. Bagian Anestesiologi dan Terapi Intensif. Fakultas Kedokteran U.I. Jakarta. 
5. Kraft M, Roundtree SL. 2007. Evaluating the Patient Before Anesthesia. In: Dunn, Peter F. Clinical Anesthesia Procedures of the Massachusetts General Hospital, 7th Edition. New York: Lippincott Williams \& Wilkins.

6. Munaf, S., 2008. Kumpulan Kuliah Farmakologi. Palembang: EGC.

7. D.S. Zulinda, Elysabeth. 2007. Obat Susuna Saraf Pusat-Anestetik Umum. Dalam: Farmakologi dan Terapi Edisi 5. Jakarta: Departemen Farmakologi dan Terapeutik Fakultas Kedokteran Universitas Indonesia.

8. Nileshwar Anitha. 2014. Instant Access Anestesiologi. Tangerang: Binarupa Aksara Publisher.

9. Morgan GE, Mikhail MS, Murray MJ, eds. 2009. Clinical Anesthesiology 4th Edition. New York: Blackwell Science.

10. Gwinnutt CL, ed. 2004. Lecture Notes Clinical Anaesthesia Second Edition. Massachusetts: Blackwell Science Ltd.

11. Carter R. 2005. Preanesthesia Evaluation. In: Gordon RC. Manipulation Under Anesthesia Concept in Theory and Application. New York: Taylor \& Francis Group.

12. Wilson I. 2004. Routine Preoperative Investigations. In: Allman K, Wilson

I. Oxford Handbook of Anaesthesia. London: UK Gateway.

13. Smart, T. 2012. Sedation and Analgesia Training Module. Available from URL: pada 15 Mei 2016.

14. Wolters U, Wolf T, Stutzer H, Schroder T. 1996. ASA Classification and PerioperativeVariables As Predictors Of Postoperative Outcome. Br J Anaes.
15. Shari M, Burns, RN. 2003. Delirium during emergence from anesthesia: acase study. J Cr.

16. Brown EN, Lydic R, Schiff ND. 2010. General anesthesia, sleep, and coma. N Engl J Med

17. Gufran Muhammad, L Diana, K Lucky.2012. Perbandingan Skor Ramsay Anastetika Inhalasi Isofluran Dibandingkan Sevofluran Pada Pasien Pasca Operasi Abdomen. Manado: Bagian Anestesiologi dan Terapi Intensif FK Universitas Sam Ratulangi.

18. Pierce A, Neil R. 2007. At a glance ilmu bedah. Alih bahasa. Umami V.Jakarta: Erlangga

19. Daniel D. Moos,2001. Anestesiologi, Jakarta: CV. Info Medika

20. McConachie I, ed. Anaesthesia For The High Risk Patient. London: Greenwich Medical Media Limited; 2002. p.215-7

21. Hebert PC, Hu L, Biro G. Review of physiological response to anaemia. Can Med Assoc J 1997; 156 (suppl. 11): S2740. 
